\title{
Ensino de História e ação comunicativa: a racionalidade processual na História ensinada
}

\begin{abstract}
RESUMO: Este artigo é fruto da pesquisa que desenvolvemos no mestrado em Educação no período de 2000 a 2003, na Universidade Federal Fluminense. Buscamos identificar em nossa pesquisa como os elementos História e memória social se constituem no espaço da sala de aula de história, produzindo assim a história ensinada. A teoria habermasiana da Ação Comunicativa é o nosso principal alicerce teórico; desta forma, buscamos relacionar esta teoria com a construção da memória social e seu papel no fazer pedagógico da sala de aula de história. A possibilidade da teoria da Ação Comunicativa fundamentar o processo pedagógico é evidenciada, destacando-se o diálogo, em movimentos dinâmicos, como o centro do procedimento pedagógico realizado em sala de aula. Apresentamos a relação entre História, Ensino de História e Memória. Desenvolvendo uma reflexão sobre a história ensinada e sua possível abordagem no espaço pedagógico. Nossas reflexões são marcadas pela racionalidade processual desenvolvida na construção da história ensinada. Pensamos a sala de aula como um espaço de coação mínima; nessa perspectiva, analisamos os nossos dados coletados à luz da teoria da Ação comunicativa habermasiana.
\end{abstract}

PALAVRAS-CHAVES: Ensino de História. Memória Social. Ação Comunicativa

\section{Os caminhos que trilhamos para pensar a história ensinada}

O ensino de história em geral é marcado por uma vertente de cunho nacionalista e burguês; no presente artigo, fruto de nossa pesquisa de mestrado, buscamos rupturas com essa tradição e saídas para um novo caminhar.

O ensino de história tem sua gênese vinculada ao nascimento do Estado nacional e ao ideário nacional. O conteúdo desta disciplina escolar é tradicionalmente marcado pelo positivismo de aspecto evolucionista, destacando em sua origem a ruptura do passado, medieval e clerical, com o presente e a construção contínua e evolutiva do futuro. É a modernidade se fazendo e deixando seu legado ideológico na ciência História; a pretensão existente na modernidade de romper com o passado fazendo um novo presente. (HABERMAS, 2000, p. 12)

A origem da disciplina escolar história marca sua trajetória pedagógica de forma relevante. Podemos encontrar sinais de uma historiografia evolucionista positivista até a atualidade nos livros didáticos, nos currículos e conteúdos definidos pelas várias secre-
Patrícia Bastos de Azevedo Professora da Universidade Federal Rural do Rio de Janeiro patriciabazev@gmail.com 
(1) História com H maiúsculo nos remeterá neste texto à história oficial, produzida pela instituiçōes historiográficas e aceita pelo poder estabelecido. tarias de educação e na tradição prática da sala de aula. A linha histórica - idade antiga, idade média, idade moderna e idade contemporânea - tem sua origem na modernidade e na perspectiva que ela produz de novos tempos, os tempos modernos. (HABERMAS, 2000, p. 9) Esta divisão impregna de tal forma o ensino de história que serve como divisora dos conteúdos nos ciclos e séries que compõem o ensino fundamental. A História, baseada na lógica da burguesia europeia ocidental, está pautada em uma concepção evolucionista e progressista, marcadamente linear, nos "principios sobre os quais continua se apoiando essa velha senhora européia que chamamos de história". (GRUZINSK, 2001, p. 387) Princípios que fundamentam o ensino de história praticado nas salas de aula, valorizando uma memória em detrimento de outra.

Os pilares que servem como sustentação para a História ${ }^{1}$ direcionam o foco do olhar e destacam uma faceta da memória. Ou melhor, constroem uma memória específica, que tem uma função ideológica muitas vezes escondida ou camuflada. "O mundo da pseudoconcreticidade é um claro escuro de verdade e engano. $O$ seu elemento próprio é o duplo sentido. (KOSIK, 1995, p. 15) Nessa perspectiva, o olhar histórico é desfocado e obscurecido para uma outra memória específica, tornando pessoas comuns não presentes na historiografia, que quando presentes são colocadas em uma perspectiva marginal, desbotada, produzindo uma amnésia, naturalizando a memória oficial e elevando-a à categoria de dogma - imutável, perene, eterno - focando a história nos dignos de memória, um culto a personalidades e vultos.

Até que ponto é eficiente a produção desta amnésia? Na sala de aula de história, a memória valorizada e apresentada, que remete à História dos dignos de memória, muitas vezes, entra em conflito com uma outra memória - a memória subterrânea - que é construída em outros espaços da vida dos estudantes, negada nos espaços escolares e direcionada para o porão do saber. A " $m e-$ mória subterrânea que, como parte integrante das culturas minoritárias e dominadas, se opõe à memória oficial". (POLLAK. 1989 , p. 5, grifo do autor)

A memória subterrânea é aquela que não está posta como História. Desta forma, é destituída de seu status e ignorada no ensino de história, em que poderia ser resgatada, produzindo no espaço escolar um diálogo entre os saberes que estão presentes em duas perspectivas: da História ciência e da história memória de vida. 
No sentido dos parágrafos anteriores, um novo fazer pedagógico pode ser concebido na condução do ensino de história. Este fazer pedagógico estabelecido deve ser alvo de análise e crítica no espaço da sala de aula. O ato de fala pode ser o fio condutor para uma nova prática e uma nova perspectiva paradigmática de encontro entre os dois saberes, muitas vezes em disputa na sala de aula de história. Nessa opção pelo ato de fala, as pretensões de validez existentes nas memórias travarão a batalha do argumento e o que está subterrâneo tornar-se-á dito e se fará presente, a história ensinada será refletida e produzida.

A História que fundamenta o ensino de história é produto da ação do historiador. Sendo assim, é um recorte da totalidade que se apresenta de forma científica. Quando é transposta para a sala de aula causa uma estranheza ao aluno. O acontecimento em uma perspectiva historiográfica não tem a mesma dinâmica das lembranças cotidianas ou da literatura. Uma História em geral desencarnada, sem o ritmo do cotidiano, que foge ao que nos é comum, está contada e apresentada de uma forma diferente do mundo da vida. Como se não fosse um olhar para tal mundo, como se fosse um olhar para uma outra materialidade, distante do mundo que nos cerca e forma.

O enquadramento da memória, seguindo uma estrutura historiográfica, em geral, salienta uma face em detrimento de outra, negando a participação de certos atores históricos e lançando holofotes em outros. Prioriza uma História, negando a existência de outras histórias. Mesmo a História que tenha como premissa destacar os alijados da grande história oficial é um recorte e um olhar que usa a lente de uma teoria e de um foco.

"Esse trabalho de enquadramento da memória têm seus atores profissionais da história". (POLLAK 1989, p. 10) Os profissionais da História constroem uma versão do passado podendo em sua construção promover uma amnésia social, escamoteando os conflitos, processos discriminatórios e personagens populares, confeccionando uma memória estática, que terá um papel que direciona a uma perspectiva de futuro estabelecido, este tipo de historiografia excludente permeia o ensino de história na maioria das salas de aula. Que futuro será esse? E o que quer esse futuro? São perguntas que, quando respondidas, apontam a uma postura politica e filosófica do historiador que construiu essa História, salientando uma memória específica e uma naturalização do posto negando a possibilidade de

R. Faced, Salvador, n.13, p.123-135, jan./jun. 2008125 
mudanças e de reconstrução de uma História que traga holofotes para outros atores, e sendo uma ação reflexiva coletivizada, que poderá produzir um futuro mais democrático.

Nas palavras de Motta (1998, p. 197):

A história é uma operação intelectual que, ao criticar as fontes, reconstruílas à luz de uma teoria, realiza uma interpretação do passado, onde o que importa não é só a noção de um consenso, mas também a do conflito.

O consenso e o conflito, próprios do fazer de algumas linhas historiográficas, em geral são ignorados no espaço da sala de aula e a História que é ensinada transforma-se em um conteúdo de cunho positivista e evolucionista não salientando as escolhas próprias do ato de interpretação e reconstrução. Silencia-se sobre o ato de construção da História e coloca-a como uma reprodução fiel do passado.

O silêncio sobre o passado pode produzir uma amnésia, mas também pode ser um alicerce para outras discussões: o que foi apagado, quando trazido à tona, poderá conduzir à construção de um novo caminhar da memória.

O ensino de história tem um longo caminho a seguir na busca de uma concepção em que a memória social trazida pelo estudante ao espaço da sala de aula tenha sua vez e valor, dialogando com a historiografia produzida, fazendo com que cada sujeito presente na dinâmica da sala de aula seja efetivamente um sujeito histórico reflexivo. Tradicionalmente, o ensino de história atua como reprodutor da historiografia posta e escolhida pelo sistema escolar, conduzindo o ato de ensinar a uma reprodução do estabelecido e definido como "verdade" ou de "maior valor".

O diálogo no espaço da sala de aula pode promover uma ação reflexiva entre memória e história - elementos tão complementares e de profunda diferença que cooabitam o ensino de história. Não estamos negando a existência dos conflitos entre a história e a memória, tampouco as categorizando como sinônimas: a pretensão deste artigo é salientar a necessidade de uma articulação entre esses dois saberes presentes na sala de aula de história, que muitas vezes são negados pelo ensino de história e pelas práticas pedagógicas consagradas nos espaços escolares. Tentamos trazer para a memória uma questão que é muitas vezes esquecida nas salas de aula de história - a História produz uma pretensão de validez, esta possui uma postura ideológica e função social. Quando 
o ensino de história torna-se cativo da História e não avalia o papel deste ensino na Escola, se faz instrumento de reprodução de uma memória específica e produtora de uma amnésia desejada. Quem deseja essa memória/amnésia? Quem sabe, quando o ensino de história transpuser a barreira da repetição da História estabelecida - geralmente apresentada em livros didáticos que têm um papel ideológico camuflado em seu corpo, muito vinculado ao ideário nacional a que já nos referimos anteriormente. A opção por uma conduta pedagógica que transporte para a sala de aula de história o fazer-se produtor da história e, não, aprendiz do passado, repetindo o posto pela historiografia e ignorando como essa argumentação foi conduzida e transformada em História, descortina-se como uma nova trajetória e possível caminhada.

\section{Nossa matriz teórica e sua relação com a história ensinada}

Neste momento queremos definir a intercessão entre a teoria habermasiana, a história ensinada e a memória, este, portanto, é o objetivo da presente seção deste trabalho.

O ensino de história como produtor de memória estável e elevada à categoria de verdade está em crise, assim como as formas tradicionais de construção e manutenção dessas memórias fabricadas ao longo dos últimos três séculos, onde a modernidade se assentou e o nacionalismo foi naturalizado, tornando-se, segundo esta vertente, uma concepção natural e inerente à humanidade. O nacionalismo muitas vezes é tratado como um elemento cultural transcendente, fundamentando uma racionalidade identitária e de segregação do diferente, aquele que não pertence à identidade nacional, onde um nascer em um Estado definiria o quem nós somos.

Habermas, ao analisar as festividades da República Federal da Alemanha, aponta uma questão central em todos os países: as cerimônias públicas comemorativas que têm como intuito o fortalecimento do sentimento nacional, porém chocam-se com o cadinho de culturas diferentes que os diversos países tornaramse nas últimas décadas. Podemos perceber o caminho que Habermas (2003, p. 79) indica para análise no trecho a seguir:

[...] as formas tradicionais de memória coletiva da nação, iniciadas pelos dirigentes e praticadas pelo povo, caíram hoje no redemoinho da refle-

R. Faced, Salvador, n.13, p.123-135, jan./jun. $2008 \mathbf{1 2 7}$ 
xão. E, através da ampliação discursiva e da pluralização interna do processo de decisão, os símbolos e cerimônias perderam o seu caráter "naturalmente" obrigatório (urwüchsig), isto é, o caráter de algo que abriga, independente da consciência e da reflexão.

Assim como as práticas tradicionais de memória, o ensino de história encontra-se nesse redemoinho de reflexões, principalmente porque sua gênese é oriunda de uma estratégia de promoção do nacionalismo e próxima a Estado/Nação constituído. Este processo de questionamento da História posta como verdade e estática chega aos espaços escolares e invade a sala de aula de história. Os alunos questionam o professor sobre o valor de se estudar história. Ao questionarem sobre o seu valor, eles apontam também uma problemática central da historiografia que aparece no ensino de história, o seu distanciamento do universo que cerca o aluno que está nas nossas salas de aula.

As reflexões sobre a história ensinada em sala de aula podem apontar novos olhares. Podemos nos questionar se uma ação reflexiva sobre o posto e imposto e, também sobre as memórias que habitam no mundo vida pode também causar um esvaziamento desta memória existente. Memórias estas que podem ser artificiais ou não, que se fazem presentes no mundo da vida, trazendo tudo para o redemoinho das reflexões e desqualificando estas memórias como objetos de valor. Um risco que podemos apontar para este viés de condução do próprio ensino de história, mas que também aponta uma nova possibilidade para o fazer didático da sala de aula.

O ensino de história na maioria das vezes está dimensionado nos dignos de memória e fundamentando uma memória vinculada ao Estado/Nação funcionando como um mito, causando estranheza ao aluno e provocando um desinteresse.

Muitas vezes a memória invade os espaços da sala de aula destituindo o que foi apresentado pelo professor como válido, pois traz em si o pano de fundo cultural que forma os alunos e se diferencia profundamente do ensino de história. O mundo da vida se fazendo presente nos espaços escolares e nas relações pedagógicas e a cultura social historicamente constituída que questiona as verdades apresentadas pela História.

A memória como elemento invasivo questiona o posto como verdade naturalizada, pois a verdade estabelecida no ensino de 
história entra em choque com as pretensões existentes no mundo da vida. Esta questão nos aproxima da teoria habermasiana e da perspectiva de compreender as relações estabelecidas na sala de aula via atos de fala.

Dois elementos são fundamentais na construção teórica deste artigo: primeiro, a ação comunicativa na sua forma reflexiva como possibilidade pedagógica e segundo, a memória social como elemento fundante das argumentações construídas no espaço da sala de aula.

Para Habermas, a ação comunicativa é necessária na construção da memória social no mundo da vida, promovendo a manutenção das tradições culturais, valores sociais e costumes, sendo passados de uma geração para outra. Desta forma, a comunicação é o meio pelo qual a memória social se efetiva no mundo da vida, e desta forma se faz presente na continuidade estabelecida pelas gerações futuras.

Acreditamos que uma matriz teórica que conjugue os elementos do diálogo e memória possibilita um novo olhar sobre o fazer pedagógico do ensino de história. Esta conjugação possibilita a valorização tanto do ato de ensinar como do papel da história na atualidade. Esses dois elementos - história e ensino - são apontados como em crise pela sociedade pós-moderna.

A sala de aula de história, vinculada a uma ação comunicativa na sua forma reflexiva, potencializa o espaço coletivo de argumentação, possibilitando a significação ou a re-significação das tradições culturais estabelecidas no mundo da vida.

O ensino de história tradicionalmente naturaliza algumas tradições culturais - artificiais ou espontâneas. A comunicação em sua ação cotidiana serve para a manutenção destas tradições culturais, fortalecendo a memória social. O espaço da sala de aula pode viabilizar um diálogo democrático que permita que o cotidiano que nos cerca seja visto para o além do estabelecido e naturalizado. Conduzir o que está estabelecido como memória social para o espaço do diálogo, possibilitando a manutenção, destruição ou reconstrução dessas tradições que nos cercam, pode ser efetivado no espaço da sala de aula de história.

A ação comunicativa na sua forma reflexiva, mediada pela argumentação, pode viabilizar o fazer pedagógico. A sala de aula não é um espaço de diálogo comum, ela é permeada por critérios e estruturas construídas na tradição escolar. Quando fazemos 
(2) Salientamos que em momento orientasse sua prática pedagógica pela teoria habermasiana. Buscamos perceber se a teoria da ação comunicativa tem possibilidade de ser efetivada no espaço da sala de aula. deste espaço um espaço de diálogo reflexivo podemos resgatar o sujeito histórico muitas vezes calados nas práticas cotidianas. Mesmo correndo o risco de desconstruir tradições estabelecidas no imaginário social, o ensino de história não pode se furtar a promover uma reflexão sobre o que está sendo ensinado. Nesta reflexão, as vozes dos alunos trarão muito da memória social e logo serão também elementos nesta prática estabelecida, que chamamos de história ensinada.

\section{O espaço da argumentação na história ensinada}

A argumentação traz para o espaço da sala de aula algumas questões confusas e obscuras, possibilitando que o ato reflexivo se torne coletivo e cooperativo, pois a fala do outro descortina um outro olhar, proporcionando uma compreensão intersubjetiva do conteúdo, tanto para os alunos como para o professor. Analisemos um evento coletado no campo de pesquisa: Os alunos tentam acertar através de uma série de possibilidades o que seria "vender a alma" - proposta apresentada pelo professor. Estas variáveis vão delineando a percepção que os alunos têm da expressão. Ao final do episódio, o professor constrói uma explicação que contém vários elementos oriundos das tentativas dos alunos. Podemos observar um movimento presente na construção da explicação proferida pelo professor. Um movimento de escuta das falas dos alunos e uma estruturação dos argumentos utilizando as falas dos alunos e assim buscando promover o entendimento e efetivar a aprendizagem.

A efetivação de um processo argumentativo nos moldes habermasianos, em sua totalidade, não foi identificado na análise dos dados, porém identificamos um processo embrionário de efetivação da ação comunicativa reflexiva ${ }^{2}$. Este processo embrionário torna-se claro quando identificamos os movimentos que são construídos no espaço da sala de aula de história.

As perguntas que em um primeiro momento eram prerrogativas do professor vão sendo buriladas e se constituindo como um ato de reciprocidade entre professor e alunos, constituindo assim um terceiro movimento que visa o entendimento mútuo e a compreensão do conteúdo que está sendo ensinado.O diálogo como elemento que fundamenta o procedimento pedagógico do professor vai percorrendo gradativamente o caminho que gera a 
história ensinada. O diálogo pauta uma busca coletiva pelo entendimento; entendimento este que possui várias dimensões.

Nessa perspectiva, o ensino/aprendizagem é uma ação cooperativa e pode se basear em uma ação de cunho comunicativo, possibilitando a coordenação de ações voltadas ao entendimento.

Retomamos nesse ponto a questão central de nossa pesquisa, a relação existente entre a história ensinada e a memória social. A memória social, permitida ou não, invade o espaço da sala de aula. No ensino de história esta invasão é mais constante e muitas vezes promotora de mal-estar pedagógico. Podemos observar como esta memória se faz presente de forma disfarçada ou ostensiva no espaço da sala de aula de história.

O professor trabalha no primeiro e no segundo bloco de aula com a perspectiva presente/passado. Solicita que os alunos partam da sociedade em que vivem para pensar a temática do bimestre - propriedade e posse. Esta abordagem traz para o meio do processo ensino/aprendizagem todo pano de fundo cultural do mundo da vida e esse pano de fundo se corporifica no ato de fala dos alunos. Destacamos que nossos dados foram coletados em uma turma em que o principal procedimento pedagógico do professor era o diálogo. O estabelecimento do diálogo trouxe para o debate em sala de aula elementos oriundos do cotidiano dos alunos e apontou as diferenças culturais existentes entre professor e alunos, bem como o quanto em nossas práticas pedagógicas presumimos que o nosso olhar sobre o que nos cerca é partilhado por todos. As diferenças de percepção de determinados conceitos e objetos, tais como: "Biscoito é alimento ou não?" ou, "Celular é necessidade ou desejo?" Estabeleceram breves momentos argumentativos, nos quais as pretensões de validez apresentadas foram questionadas e, como validades criticáveis, possibilitaram a efetivação do processo argumentativo.

A existência da polêmica por si só não garantiria o estabelecimento do processo argumentativo. Este processo só pode ser efetivado, mesmo que de forma precária, porque o diálogo de cunho democrático era o fio condutor do procedimento pedagógico estabelecido e, desta forma, os atores da fala puderam expressar suas discordâncias e aceitações em relação à pretensão proferida. Não estamos afirmando que o processo argumentativo, segundo a teoria habermasiana, foi efetivado nos episódios que analisamos em nossa dissertação de mestrado, estamos apontando que este

R. Faced, Salvador, n.13, p.123-135, jan./jun. $2008 \mathbf{1 3 1}$ 
processo teve início e que esse viés de possibilidade pode ter espaço na ação pedagógica nos espaços de sala de aula.

Outro elemento é fundamental neste processo, a importância do pano de fundo cultural na construção argumentativa que utilizamos para apresentar uma pretensão de validez ou criticar uma pretensão apresentada por um outro ator. Nesse aspecto, muitas vezes o ensino de história não viabiliza uma relação argumentativa, porque na maioria das vezes ele está baseado na pretensão que a História é única e o papel do aluno é aprendê-la.

Em uma perspectiva dialógica, a História que é ensinada no espaço da sala de aula é apresentada como uma versão da história e, sendo assim, pode ser criticada. Não estamos desmerecendo a importância dos conteúdos selecionados para as diversas séries e ciclos, nos diversos níveis do ensino, somente estamos tentando indicar uma possibilidade para a caminhada. Na perspectiva que apresentamos neste artigo, buscamos a possibilidade de relação entre ensino de história e memória social. E vislumbramos esta possibilidade via ação comunicativa reflexiva.

A nossa análise apontou o diálogo como instrumento pedagógico que pode viabilizar a efetivação do agir comunicativo voltado ao entendimento. Confirmamos um elemento que fundamentou nossa investigação desde seu estágio mais embrionário - que a memória social invade o espaço da sala de aula queiramos ou não. Administrar esta invasão requer muito mais que boa vontade, requer de nós um aprofundamento pedagógico e a condução de uma postura pedagógica mais democrática. Encontramos na teoria habermasiana da ação comunicativa elementos para construirmos uma história ensinada mais comprometida com a formação do cidadão que pode perceber os diferentes mundos da vida e partilhar o cotidiano com o diferente: valorizando o respeito coletivo, as diferenças que estão na escola e no mundo, que porém muitas vezes nós as ignoramos, ou as relegamos ao esquecimento em prol de uma suposta verdade única.

Percebemos em nossa pesquisa como a História não é única, como o pano de fundo cultural dos mundos da vida também não o são. E essas multiplicidades de realidades e visões acerca do mundo da vida se fazem presentes no espaço da sala de aula. E nos lançam uma pergunta: O que ensinar então? Talvez devamos pensar em um ensino das histórias e implantarmos no espaço 
pedagógico um processo argumentativo, que busque mais que salientar as diferenças, busque produzir o entendimento mútuo e a cooperação solidária entre os atores.

Não propomos uma solução para os problemas que afligem a sala de aula de história, e muito menos solução para a questão que nos motivou no início de nossa pesquisa. Fizemos nossa jornada e como peregrino contamos o que descobrimos e indicamos algumas possibilidades de caminhos. Acreditamos firmemente que a escola é um espaço que pode, ou melhor, tem o dever de promover a democracia. Vislumbramos, na teoria da Ação Comunicativa, elementos que viabilizam a implementação do processo democrático em sala de aula. Reconhecemos alguns limites sociais que impossibilitam a aplicação plena desta teoria, porém elementos fundamentais são viáveis no cotidiano da sala de aula.

A publicidade e a inclusão de todos os atores; a aceitação de que a controvérsia promove o debate e pode possibilitar contribuições importantes para o processo de ensino aprendizagem. Excluir os enganos, subterfúgios e ilusões. Promover a não-coação comunicativa e buscar o melhor argumento, possibilitando assim a existência de consenso. Estes são elementos da teoria da Ação Comunicativa que identificamos como possíveis de serem efetivadas no espaço escolar.

Nesta perspectiva dialógica e argumentativa, a memória social torna-se mais visível e copartícipe da história ensinada, pois se materializará nos atos de falas. E os elementos naturalizados na memória social, tais como: "Sempre foi assim"; "A história foi sempre a mesma"; e tantos outros que invadem a sala de aula podem ser desnaturalizados e, quem sabe, nossa ação pedagógica seja mais eficaz e promotora de uma democracia mais real.

A memória social não se cala. Mesmo que a ignoremos ela se introduz na sala de aula. Na sala de aula de história sua intromissão é mais frequente e contumaz, pois a memória é um elemento inerente ao ensino de história. Acreditamos que o diálogo argumentativo cria a possibilidade de articularmos memória social e História, viabilizando uma análise coletiva e cooperativa, produtora de uma memória social fruto da reflexão, que pode transbordar o fazer da sala de aula de história para outros espaços sociais. 


\section{Teaching History and Communicative Action: the processual rationality on Taught History}

ABSTRACT: This paper was resulted from the dissertations of Master in Education developed between 2000 and 2003 in Universidade Federal Fluminense. We tried to identify how aspects of History and Social Memory within the classroom of history produce a Taught History. Haberman Theory of Comunicative Action is the theoretical background of the research. Thus, the study has focused in the relationship between this theory and social memory construction, and how its role in the pedagogical action in history lessons. The possibility of the communicative theory supporting the pedagogical process is highlighted as centre of the dynamics of dialogue in classroom. we present The relationship among History, Taught History and Memory developing a reflection about Taught History and its possible approach to the pedagogical space. Our reflections show the processual rationality developed in the construction on Taught History. The classroom is considered as a space of minimum coercion. In this perspective we analyze the collected data highlighted in the habermasian Theory of Communicative Action.

KEYWORDS: Teaching History, Social Memory, Communicative Action

\section{Referências}

AZEVEDO, Patrícia Bastos de. Ensino de historia e memória social: a construção da história-ensinada em uma sala de aula dialógica. 2003. Dissertação (Mestrado) - Universidade Federal Fluminense, Niterói, 2003.

GONTIJO, Rebeca. Identidade nacional e história: a diversidade como "patrimônio sócio-cultural". In: ABREU, Martha; SOIHET, Rachel (Org.). Ensino de história: conceitos, temáticas e metodologia. Rio de Janeiro: Casa da Palavra, 2003.

GRUZINSKI, Serge. Acontecimento, bifurcação e acaso... observações sobre a história a partir das periferias do Ocidente. In: MORIN, Edgar (Org.). Jornadas temáticas. Rio de Janeiro: Bertrand Brasil, 2001.

HABERMAS, Jürgen. Agir comunicativo e razão destranscendentalizada. Rio de Janeiro: Tempo Brasileiro, 2002.

Consciência moral e agir comunicativo. Rio de Janeiro: Tempo Brasileiro, 1998.

Era das transições. Rio de Janeiro: Tempo Brasileiro, 2003.

- O discurso filosófico da modernidade: doze lições. São Paulo: Martins Fontes, 2000.

Passado como futuro. Rio de Janeiro: Tempo Brasileiro, 1993.

Pensamento pós-metafísico: estudos filosóficos. Rio de Janeiro:

Tempo Brasileiro, 1990.

Teoría de la acción comunicativa: complementos y estudios previos. 3. ed. Madri: Cátedra, 1997. 
HOBSBAWN. Eric J. Nações e nacionalismo desde 1780: programa, mito e realidade. Rio de Janeiro: Paz e Terra, 1990.

; RANGER, Terence (Org.). A invenção das tradições. 2. ed. São Paulo, Paz e Terra, 1997.

KOSIK, Karel. Dialética do concreto. 2. ed. Rio de Janeiro: Paz e Terra, 1995.

LE GOFF, Jacques. História e memória. 4. ed. Campinas, São Paulo: UNICAMP, 1996.

MOTTA, Márcia Maria Menendes. Jogos de memória: conflito de terra e amnésia social. Tempo: Revista do Departamento de História da UFF, v. 3, n. 6, p. 183-198, 1998.

POLLAK, Michael. Memória e identidade social. Estudos Históricos, Rio de Janeiro, v. 5, n. 10, 1992, p. 200-212.

Memória, esquecimento, silêncio. Rio de Janeiro, Estudos Históricos, v. 2, n. 3, p. 3-15, 1989.

RICOEUR. Paul. O passado tinha um futuro. In: MORIN, Edgar (Org.). Jornadas temáticas. Rio de Janeiro: Bertrand Brasil, 2002. 